\title{
Erro odontológico no serviço público: jurisprudências em pedidos de indenizações civis
}

\author{
Dental malpractice in public health: jurisprudence survey in civil claims
}

Error dental en el servicio público: jurisprudencia en reclamaciones de indemnización civil

Ricardo José Nazar

ORCID: https://orcid.org/0000-0001-9075-0005 Universidade Federal de Minas Gerais, Brasil E-mail: ricardonazarbh@yahoo.com.br

Rosa Núbia Vieira de Moura

ORCID: https://orcid.org/0000-0002-8947-2797 Universidade Federal de Minas Gerais, Brasil E-mail: bdmoura96@gmail.com

Efigênia Ferreira e Ferreira

ORCID: https://orcid.org/0000-0002-0665-211X Universidade Federal de Minas Gerais, Brasil E-mail: efigeniaf@gmail.com

Denise Vieira Travassos

ORCID: https://orcid.org/0000-0003-2084-9557

Universidade Federal de Minas Gerais, Brasil E-mail:detravassos@gmail.com

\begin{abstract}
Resumo
Objetivo: conhecer e analisar processos por erro odontológico contra cirurgiões-dentistas, exercendo função pública. Metodologia: pesquisa de decisões nos sites dos Tribunais de Justiça de Minas Gerais, Amazonas, Ceará, Rio de Janeiro, Santa Catarina e Distrito Federal no período entre 2014 e 2019, foi realizada uma pesquisa qualitativa, análise documental, a partir das ementas encontradas com base em roteiro proposto. Resultados: Constatou-se um número pequeno de demandas contra cirurgiões-dentistas no exercício de funções no âmbito do serviço público, nos tribunais de justiça estudados. Foi identificado um total de 10 processos, sendo eles: 2 em Minas Gerais, 0 no Amazonas, 2 no Ceará, 2 Rio de Janeiro, 3 Santa Catarina e 2 no Distrito Federal. Quanto às variáveis analisadas: 100\%, foram contemplados com assistência judicial gratuita; apenas o ente público foi acionado judicialmente; quando encontrado o dado, a responsabilidade objetiva foi atribuída ao ente demandado; houve predomínio do dano conjunto material/moral; houve decisão desfavorável ao ente público na maioria dos processos e os procedimentos de maior frequência foi de cirurgia. Conclusão: Apesar do pouco número de processos encontrados, o estudo pode ser considerado preliminar para uma análise mais profunda da responsabilidade pública na prestação de serviços odontológicos como forma de compreender como o fenômeno reclamação dos pacientes ocorre no Sistema Único de Saúde, o que permitirá que medidas preventivas e corretivas possam ser tomadas.

Palavras-chave: Cirurgião-dentista; Atenção odontológica; Responsabilidade civil; Pesquisa nos serviços de saúde; Imperícia.

Abstract

Objective: recognize and analyze cases of dentistry error against dentists, exercising public function. Methodology: decision research on the sites of the Courts of Justice of Minas Gerais, Amazonas, Ceará, Rio de Janeiro, Santa Catarina and the Federal District in the period between 2014 and 2019 based on the proposed script. Results: There was a small number of demands against dentists in the exercise of functions within the public service, in the courts of justice studied. A total of 10 processes were identified, namely: 2 in Minas Gerais, 0 in Amazonas, 2 in Ceará, 2 in Rio de Janeiro, 3 in Santa Catarina and 2in the Federal District. As for the variables analyzed: $100 \%$ received free legal assistance; only the public entity was sued; when the data was found, objective responsibility was assigned to the respondent; there was a predominance of joint material/moral damage; there was an unfavorable decision to the public entity in most cases and the most frequent procedures were surgery. Conclusion: Despite the small number of cases found, the study can be considered preliminary for a deeper analysis of public responsibility in the provision of dental services as a way to understand how the phenomenon of patient complaints occurs in the Unified Health System, which will allow preventive and corrective measures can be taken.
\end{abstract}

Keywords: Dentist; Dental care; Damage liability; Health services research; Malpractice. 


\begin{abstract}
Resumen
Objetivo: conocer y analizar procesos de error profesional contra odontólogos, ejerciendo cargo público. Metodología: investigación en los sitios web de los Tribunales de Justicia de Minas Gerais, Amazonas, Ceará, Rio de Janeiro, Santa Catarina y el Distrito Federal en el período entre 2014 a 2019. Se realizó una investigación cualitativa, análisis documental, de la decisions judiciais encontrados, basados en el guión propuesto. Resultados: Hubo un número reducido de demandas contra los odontólogos en el ejercicio de funciones dentro del servicio público en los tribunales de justicia estudiados. Se identificaron un total de 10 procesos, a saber: 2 en Minas Gerais, 0 en Amazonas, 2 en Ceará, 2 en Río de Janeiro, 3 en Santa Catarina y 2 en el Distrito Federal. En cuanto a las variables analizadas: el 100\% recibió asistencia jurídica gratuita; sólo se demandó a la entidad pública; cuando se encontraron los datos, se asignó responsabilidad objetiva; predominó el daño material / moral conjunto; hubo una decisión desfavorable a la entidad pública en la mayoría de los casos y los procedimientos más frecuentes fueron de cirugía. Conclusión: a pesar del escaso número de casos encontrados, el estudio puede considerarse preliminar para un análisis más profundo de la responsabilidad pública en la prestación de servicios odontológicos como una forma de entender cómo se da el fenómeno de las quejas de los pacientes en el servicio publico de salud, lo que permitirá medidas preventivas y correctivas.
\end{abstract}

Palabras clave: Odontólogos; Atención odontológica; Responsabilidad civil; Investigacion sobre servicios de salud; Mala praxis.

\title{
1. Introdução
}

Até poucos anos atrás, eram raros os casos que chegavam aos tribunais e envolviam a responsabilidade do profissional de saúde. Atualmente, no entanto, esse tipo de ação se tornou mais comum, especialmente com o advento da Lei de Proteção ao consumidor, segundo a qual o paciente, agora, conhecedor dos seus direitos, encara a sua relação com o profissional de saúde como uma relação de consumo (Silva, 1999). Cobra-se por meio de leis, a responsabilidade desses profissionais, incluindo o cirurgião dentista. do cirurgião dentista.

Em processos, a responsabilidade é categorizada em civil, penal e administrativa, ou seja, se a o fato gerador puder ser caracterizado como ilícito civil poderá ser apurada a responsabilidade civil. Se for caracterizado como crime pela norma penal haverá a possibilidade de arguição da responsabilidade penal. Por fim, se o fato tiver violado alguma norma administrativa há a consequentemente a possibilidade de verificação da responsabilidade administrativa (Di Pietro, 2014).

O conceito de responsabilidade civil ligado ao prejuízo de terceiros está relacionado à obrigação de reparar o dano imposto à vítima, de modo a restabelecer a situação anteriormente existente ou, caso não seja possível, compensando-a pelo infortúnio decorrido do fato (Caixeta, 2008). Diversos fatores são originários da responsabilidade civil, entre eles, destaca-se: o descumprimento obrigacional, inadimplemento contratual, ou simplesmente o fato de não se respeitar um preceito normativo que regula a vida em sociedade (Pereira, 2004; Albuquerque, 2011).

Para Pereira (1999), na responsabilidade civil, a reparação do dano fica vinculada à pessoa causadora do prejuízo, e, como se fala em "causador do dano", não se questiona se houve culpa ou não. Em qualquer hipótese que seja determinado que um indivíduo deverá indenizar um sujeito passivo, restará caracterizada responsabilidade civil.

Segundo Moraes (2009), a responsabilidade civil do Estado é a teoria do risco administrativo que pode ser definida como o dever de ressarcimento dos danos causados a terceiros, independente da configuração de dolo ou culpa.

Não é necessária a comprovação da culpa do Estado em relação ao fato danoso, isto por causa da sua responsabilidade objetiva, sendo apenas necessário comprovar o nexo causal entre o fato e o dano (Carvalho Filho, 2014). Aduz ainda o referido autor que, na medida em que se tornou visível o poder do Estado em relação ao administrado, este tem o dever de arcar com os riscos naturais resultante das suas diversas atividades, por ser mais poderoso, dando origem, por isso, à teoria do risco administrativo.

Com isso, a responsabilidade civil do Estado frente aos seus agentes públicos, é de ressarcir todo e qualquer indivíduo que se sinta lesado frente à má administração da coisa pública. Mas, é certo dizer que existem limites à responsabilidade do Estado decorrente do Risco Administrativo, os quais são: força maior ou culpa exclusiva da vítima. 
A Constituição Federal garante ao Estado o direito de regresso, caso demonstrado dolo ou culpa do agente público. Sendo assim, quando o dano é causado a terceiro por determinado servidor público, aplica-se a norma prevista no artigo 37, § $6^{\circ}$ da $\mathrm{CF} / 88$, visto que o Estado responde objetivamente, independente de culpa ou dano. No entanto, pode o Estado, neste caso, de acordo com a Constituição Federal (Brasil, 1988), impetrar uma ação de regresso contra o servidor que gerou o dano, como já descrito acima. Contudo, mesmo diante das normativas protetivas vigentes, acredita-se que o usuário dos serviços públicos de saúde, pratica seu exercício de cidadania ainda de maneira incipiente, trazendo poucas demandas judiciais com esse fulcro.

Esse estudo tem como objetivo analisar as decisões de processos por erro odontológico contra cirurgiões-dentistas exercendo função pública, encontrados nos sites dos Tribunais de Justiça de seis estados brasileiros, no período de 2014 a 2019, quando a finalidade for o ressarcimento por danos causados.

\section{Metodologia}

Trata-se de estudo descritivo, que buscou analisar as ementas encontrados nos sites de Tribunais Justiça de estados brasileiros, no período de 2014 a 2019.

Como critérios de inclusão foram analisados apenas aqueles processos judiciais que envolviam reclamações contra serviços prestados por cirurgiões-dentistas, em exercício de função pública, relacionados a pedido de indenização por tratamentos realizados na instituição pública.

Para a escolha dos estados participantes, foi feito o sorteio aleatório, por meio do programa Excel-Microsoft 365, obtendo-se um Estado de cada região brasileira. O Estado de Minas Gerais foi incluído na amostra, intencionalmente, por ser o local de desenvolvimento da pesquisa.

Os relatórios de jurisprudência só podem ser localizados em sites de Tribunais de Justiça, quando o processo não corre em segredo de justiça. Deste modo são publicados em locais de livre acesso.

A busca por documentos foi realizada em sites dos tribunais dos estados incluídos no estudo, por um único pesquisador, a partir do acesso aos endereços apontados no Quadro 1, consulta a processos.

Quadro 1. Tribunais Brasileiros pesquisados, siglas e respectivos sites buscados.

\begin{tabular}{|c|c|c|}
\hline Tribunal de Justiça & Sigla & Site \\
\hline Minas Gerais & TJMG & https://www.tjmg.jus.br/portal-tjmg/ \\
\hline Amazonas & TJAM & https://www.tjam.jus.br \\
\hline Ceará & TJCE & https://www.tjce.jus.br/ \\
\hline Rio de Janeiro & TJRJ & http://www.tjrj.jus.br/ \\
\hline Santa Catarina & TJSC & https://www.tjsc.jus.br/ \\
\hline Distrito Federal & TJDFT & https://www.tjdft.jus.br/ \\
\hline
\end{tabular}

Fonte: Autores.

Em cada um dos sites, procurou-se o por "consulta às jurisprudências". Como critérios de busca, foram utilizadas as palavras-chave: "dentista"; "cirurgião-dentista"; "tratamento odontológico" e "erro odontológico", com os filtros: "serviço público"; "sistema único de saúde"; "Estado" e "município".

Segundo Cellard (2012), a autenticidade e a confiabilidade dos textos deve ser um dos critérios de avaliação dos documentos a serem analisados, e nesse caso, serão analisados alguns trechos de um processo jurídico. Outro critério de igual importância se refere aos conceitos-chave e a lógica interna do texto. Não se pode desconsiderar o componente subjetivo de um julgamento, com forte ligação à visão de mundo do julgador. Mas os passos seguidos no processo seguem leis e portanto, 
partem de uma mesma base: a legislação vigente o que minimiza as diferenças. Deste modo são passiveis de serem analisados em conjunto, respeitando-se as especificidades.

Após a coleta dos dados, cada decisão judicial foi analisada, os dados registrados em planilha e analisados.

O roteiro norteador da análise incluiu informações acerca dos seguintes itens processuais: 1. Assistência Judiciária gratuita: presente ou ausente; 2. Agente passivo: profissional e/ou ente público; 3. Tipo de responsabilidade; 4. Tipo de obrigação; 5. Tipo de dano alegado; 6. Decisão judicial; 7. Procedimento Envolvido. Estas informações foram analisadas em seu conteúdo para que pudessem ser compreendidas.

Segundo as normas estabelecidas pela Resolução $n^{\circ}$ 466/12, não houve necessidade de submissão deste trabalho à análise do Comitê de Ética em Pesquisa, uma vez que os dados trabalhados estão, publicamente, disponibilizados nos sites dos Tribunais de Justiça envolvidos no estudo. Entretanto, foram garantidos sigilo e anonimato dos dados de pacientes e profissionais analisados.

\section{Resultados}

No período de 2014 a 2019, nos Tribunais de Justiça dos estados citados foi identificado um total de 10 processos, referentes a cirurgiões-dentistas exercendo função pública, denunciados por erro, distribuídos conforme descrito na Tabela 1, sendo eles: 2 em Minas Gerais, 0 no Amazonas, 2 no Ceará, 2 Rio de Janeiro, 3 Santa Catarina e 2 no Distrito Federal. Quanto às variáveis buscadas no total de processos encontrados: $100 \%$, foram contemplados com assistência judicial gratuita; apenas o ente público foi acionado judicialmente; quando encontrado o dado, a responsabilidade objetiva foi atribuída ao ente demandado; houve predomínio do dano conjunto material/moral; houve decisão desfavorável ao ente público, na maioria dos processos e os procedimentos que maior frequência nas demandas foram de cirurgia.

Tabela 1. Processos relacionados a tratamentos odontológicos, realizados por cirurgiões-dentistas, exercendo função pública segundo o Tribunal de Justiça consultado, Brasil, 2014-2019.

\begin{tabular}{|c|c|c|c|c|c|c|c|c|}
\hline \multirow[t]{2}{*}{ Itens processuais } & \multirow[t]{2}{*}{ Categorias } & \multicolumn{7}{|c|}{ Processos identificados/TJ } \\
\hline & & MG & AM & $\mathrm{CE}$ & $\mathrm{RJ}$ & SC & DF & $\mathrm{T}$ \\
\hline \multirow[t]{2}{*}{ Assistência Judiciária } & Sim & 2 & 0 & 2 & 2 & 3 & 1 & 10 \\
\hline & Não & 0 & 0 & 0 & 0 & 0 & 0 & 0 \\
\hline \multirow[t]{2}{*}{ Agente Passivo } & Público & 2 & 0 & 2 & 2 & 3 & 1 & 10 \\
\hline & Profissional & 0 & 0 & 0 & 0 & 0 & 0 & 0 \\
\hline \multirow[t]{3}{*}{ Caracterização do Ente Público } & Estado & 1 & 0 & 0 & 1 & 0 & 0 & 2 \\
\hline & Município & 1 & 0 & 1 & 1 & 3 & 1 & 7 \\
\hline & Ambos & 0 & 0 & 1 & 0 & 0 & 0 & 1 \\
\hline \multirow[t]{3}{*}{ Responsabilidade } & Objetiva & 2 & 0 & 2 & 2 & 0 & 0 & 6 \\
\hline & Subjetiva & 0 & 0 & 0 & 0 & 0 & 0 & 0 \\
\hline & Sem relato & 0 & 0 & 0 & 0 & 3 & 1 & 4 \\
\hline \multirow[t]{3}{*}{ Obrigação } & Meio & 0 & 0 & 0 & 0 & 0 & 0 & 0 \\
\hline & Resultados & 2 & 0 & 0 & 2 & 0 & 0 & 6 \\
\hline & Sem relato & 0 & 0 & 2 & 0 & 3 & 1 & 4 \\
\hline \multirow[t]{4}{*}{ Dano Alegado } & material & 1 & 0 & 0 & 0 & 0 & 0 & 1 \\
\hline & moral & 0 & 0 & 0 & 2 & 0 & 0 & 2 \\
\hline & ambos & 1 & 0 & 2 & 0 & 1 & 1 & 5 \\
\hline & Não relatado & 0 & 0 & 0 & 0 & 2 & 0 & 2 \\
\hline \multirow[t]{3}{*}{ Decisão Judicial } & Absolvido & 0 & 0 & 1 & 0 & 1 & 1 & 3 \\
\hline & Condenado & 2 & 0 & 1 & 2 & 0 & 0 & 5 \\
\hline & Sem relato & 0 & 0 & 0 & 0 & 2 & 0 & 2 \\
\hline
\end{tabular}

Fonte: Dados da pesquisa (2020). 


\section{Discussão}

O estudo encontrou uma pequena quantidade de processos de ressarcimento por tratamentos odontológicos no serviço público no período estudado (10), confirmando o que se tinha como hipótese de pesquisa. No entanto, a análise dos resultados pode fornecer elementos para a compreensão do fenômeno na esfera pública.

No Estado de Santa Catarina, dos 3 (três) processos encontrados dois estão em segredo de justiça, não constam na integra, e dessa forma, não há como verificar todos os pontos relevantes nos mesmos, como por exemplo, tipo de personalidade, tipo de obrigação e se réu foi condenado ou absolvido.

Não foram encontrados processos no Estado do Amazonas. Esse achado pode ser reflexo da característica da região em relação à política nacional de saúde bucal, pois, de forma contraditória, observa-se que, embora a região Norte apresente indicadores sociais desfavoráveis com elevada taxa de analfabetismo, baixo rendimento mensal familiar e a pequena cobertura de domicílios com saneamento público, apontando diversas necessidades e deficiências, ela possui menos investimentos na saúde bucal quando comparados à região sudeste, por exemplo, tendo, portanto, menor cobertura na atenção odontológica (Saliba et al, 2010). A dificuldade e a escassez de acesso ao serviço público pode ser um fator que leve o usuário a não reclamar dos serviços prestados na região.

Quantos aos procedimentos envolvidos nas ações foram encontrados procedimentos de cirurgia/exodontia em 6 processos, uma reclamação por restauração provisória e uma por tratamento restaurador. Esse achado difere do encontrado em outros estudos que estudaram processos contra dentistas na área privada uma vez que as especialidades mais demandadas quase sempre são a implantodontia, ortodontia e reabilitação oral (Wanderley \& Lima et al, 2012; Lyra et al, 2019; Bento et al, 2021; Mendes et al, 2021). Esta diferença pode ser consequência do fato de que as especialidades mencionadas são de alta complexidade que não são ofertadas com ampla cobertura populacional como os procedimentos de atenção básica, do qual fazem parte os encontrados nas demandas.

A totalidade das ações encontradas estavam sob a assistência judiciária. Os usuários do Sistema único de Saúde, que são os reclamantes das ações estudadas, recorreram à justiça para reclamar do serviço público prestado, supostamente de forma equivocada, através de um instituto que garante acesso gratuito também à justiça, como foi o serviço de saúde prestado. O que demostra a importância da possibilidade de recorrer ao judiciário como forma de garantir os direitos fundamentais, sendo uma forma de assegurar a tutela desses mesmos direitos. O próprio Estado deve viabilizar, através de normas e procedimentos, que este acesso seja possível a todos.

A Constituição Federal procura garantir legalmente essa assistência, promovendo meios formais de proteção, ao dispor no art. $5^{\circ}$, LXXIV, que "o Estado prestará assistência jurídica integral e gratuita aos que comprovarem insuficiência de recursos". Há, ainda, a previsão de um órgão estatal, a Defensoria pública, no artigo 134, e atribui a este a orientação jurídica e a defesa, em todos os graus dos necessitados, na forma da lei (Brasil, 1988).

A Lei Federal de 05/02/50, mas que ainda está em vigor, assegura assistência judiciária ao hipossuficiente economicamente, considerado pela lei, em seu art. $2^{\circ}$ como "aquele cuja situação econômica não lhe permita pagar as custas do processo e os honorários de advogado, sem prejuízo do sustento próprio ou da família” (Brasil, 1950). A assistência judiciária refere-se ao fato de ser o Estado obrigado a oferecer um representante na ação para assistir ao demandante no processo. Esta obrigação estatal pode ser desempenhada por advogados, principalmente, ou através de instituições que prestam o serviço gratuitamente (Pierri, 2008).

Nos processos encontrados o paciente ao se sentir lesado demandou diretamente e apenas o ente público, tendo sido a responsabilidade considerada objetiva em seis processos. A caracterização da responsabilidade do Estado como o objetiva, estabelece a obrigatoriedade para o ofendido de apenas provar o dano, o nexo causal e a conduta atribuída ao agente público, 
dispensando a necessidade de provar a culpa do Estado (Moraes, 2009; Carvalho Filho, 2014). Esse fato facilita ao procurador do paciente na fundamentação processual uma que a teoria do risco administrativo, que é a mais adotada no nosso ordenamento jurídico, tem como regra a inversão do ônus da prova. Desta forma, caso o paciente que tenha sido vítima de ato danoso no exercício de um profissional de saúde, conseguir comprovar o dano à sua saúde, caberá ao ente público se defender demonstrando a inexistência dos pressupostos necessários para caracterizar a obrigação de indenizar.

O sistema de saúde brasileiro foi regulamento pela Lei 8080/90, Lei Orgânica da Saúde, que disciplina no território nacional, os serviços e ações em saúde. O artigo define, ainda, em seu inciso IX, a divisão administrativa descentralizada, regionalizada e hierarquizada das ações e serviços de saúde. Por outro lado, estabelece a integração, em nível executivo e a conjugação dos recursos financeiros, tecnológicos, materiais e humanos das três esferas. Na divisão de atribuições cabe aos Municípios a execução de ações e serviços de menor complexidade, aos Estados os de média e alta complexidade e à União as de alta complexidade (Brasil, 1990). A assistência odontológica quase sempre cabe aos municípios, o que poderia explicar o maior número de ações contra esse ente. pois os recursos financeiros, bens e insumos devem ser destinados aos procedimentos clínicos odontológicos, complementares aos realizados na atenção básica, que é função do município (Saliba et al, 2010).

Foi encontrado um processo no qual os dois entes públicos foram demandados de forma simultânea, a situação deve ser analisada uma vez que as políticas públicas de saúde bucal têm um processo de implantação co-participativo, com parcelas contributivas de Estados e municípios (Saliba et al, 2010). O artigo 23 da Constituição Federal (Brasil,1988), que estabelece a obrigação de cuidar da saúde como de competência comum da União, Estados, Distrito Federal e Municípios é dispositivo legal para o fundamento de defesa da tese de haver uma responsabilidade solidária do poder público como um todo, em garantir a saúde do cidadão. Essa pode ser alternativa do paciente em garantir a efetivação do seu direito à indenização.

O tipo de obrigação, quando encontrado foi sempre de resultado. Essa obrigação determina que o prestador de serviço, no caso o Estado, tem o dever de obter determinado resultado e, caso não obtenha sucesso, deve responder pelas consequências na ausência do êxito. Estudos realizados que pesquisaram a responsabilidades de pessoas particulares como prestadores de serviços em odontologia, seja física ou jurídica, encontraram o mesmo entendimento em relação à odontologia. A maioria das decisões, consideradas pelos magistrados como sendo de resultado. Além de uma maior tendência à condenação do prestador de serviço odontológico quando foi considerada a natureza obrigacional de resultado, quando comparada à de meios (Bento et al, 2021; Lyra et al, 2019).

A argumentação utilizada para fundamentação da obrigação de resultados quase sempre é a previsibilidade da odontologia, pois consideram que a obtenção de um determinado resultado é mais objetivamente possível, em virtude dos avanços tecnológicos. Além disso, alguns autores consideram que a sintomatologia, a diagnose e a terapêutica são mais definidas e portanto, é mais fácil para o profissional comprometer-se a curar. Desta forma, a técnica e os conhecimentos científicos existentes garantem que o dentista obtenha o resultado almejado, salvo a ocorrência de excludentes de responsabilidade como o caso fortuito, a força maior, a culpa exclusiva da vítima ou o fato de terceiro (Oliveira, 1999).

$\mathrm{Na}$ análise do dano reclamado observa-se uma maior ocorrência de pedidos de indenização por ambos, dano moral e material. O dano material em caso de tratamentos realizados pelo serviço público não envolve o ressarcimento do valor pago à prestação do serviço em si, uma vez que não é remunerado de forma direta, mas o paciente requerente pode pedir o ressarcimento de valores gastos com eventuais despesas com medicamentos ou qualquer outra medida necessária em função do dano sofrido acrescido do valor estimado para a reexecução dos trabalhos odontológicos. Geralmente, ao dano material acresce-se o dano moral, tecnicamente chamado de dano imaterial, uma vez que não produz prejuízo no patrimônio do ofendido, e cujo valor será arbitrado pelo juiz. A tendência do paciente em pedir o ressarcimento de ambos os danos também é observada nos processos envolvendo dentistas em clínicas particulares (Ferreira et al., 2018; Bento et al, 2021). 
Dos processos nos quais foi possível ter acesso à decisão judicial, observou-se uma tendência à condenação do prestador de serviço, no caso estudado o ente público. Estudos de processos envolvendo dentistas na esfera particular tem demonstrado o mesmo aspecto quanto às decisões (Mendes et al, 2021), indicando que os magistrados podem estar dando tratamento igualitário nas análises judiciais aos tratamentos odontológicos prestados tanto por entes públicos como por particulares.

Com isso, entende-se que, os responsáveis por qualquer dano provocado por um atendimento deficiente, no caso do ente público são o profissional responsável pelo atendimento, o município e/ou Estado. Assim, ao sofrer algum dano provocado por um atendimento deficiente é necessário que a "vítima" recolha o máximo de provas possíveis, juntamente com um advogado e entre com uma ação pedindo uma indenização do profissional causador do dano. Assim, os cirurgiõesdentistas, sejam eles profissionais liberais ou públicos, responderão igualmente sob o ponto de vista subjetivo.

Importante lembrar que não foi objeto de levantamento as reclamações contra os serviços prestados nos órgãos de defesa e proteção aos consumidores, que são os que tem competência para executar a política estadual para o equilíbrio nas relações de consumo, atendendo individual ou coletivamente os consumidores, fiscalizando o mercado, e promovendo a educação para o consumo, seja ela de entes públicos ou privados, sendo outra área a ser pesquisada a frequência de reclamações e que não foi objeto de análise do presente estudo (Paula, 2013) e que essa pode ser mais uma alternativa para reclamações contra os serviços prestados por dentistas no serviço público mas sem a característica de possibilidade de ressarcimento pecuniário.

\section{Conclusão}

Diante da análise dos dados encontrados o presente estudo observou um pequeno número de processos contra serviços prestados por dentistas no setor público. O ente público foi o único réu encontrado, sendo que os pacientes foram contemplados com assistência judicial gratuita em todos os processos analisados e, quando encontrado o dado, a responsabilidade objetiva foi atribuída ao ente demandado com predomínio do pedido de indenização em conjunto do dano material/moral, as decisões encontradas foram desfavoráveis ao ente público, na maioria dos processos e os procedimentos com maior frequência nas demandas foram de cirurgia.

Esse estudo pode ser considerado preliminar para uma análise mais profunda da responsabilidade pública na prestação de serviços odontológicos uma vez que não foram encontrados similares, o que demonstra que mais estudos na área devem ser realizados para compreender como o fenômeno reclamação dos pacientes está dentro do Sistema Único de Saúde o que permitirá que medidas preventivas e corretivas possam ser tomadas.

\section{Referências}

Albuquerque, H. P. J. Responsabilidade Civil dos Cirurgiões-dentistas em Razão de Procedimentos Estéticos. (2011). Revista da Universidade Federal de Santa Catarina, 1(1).

Bento, M. I., Rosa, G. C., Maciel, D. R., Biazevic, M. G. H., Santiago, B. M., \& Crosato, E. M. (2021). Análise das sentenças de processos judiciais envolvendo a odontologia julgados em primeira instância no tribunal de justiça de são paulo no ano de 2019. Revista Brasileira de Odontologia Legal, 8(1).

Brasil. Lei Federal 1060 de 05 de fevereiro de 1950. (1950). Estabelece normas para a concessão de assistência judiciária aos necessitados. Diário Oficial da União de 13 fev.

Brasil. Constituição da República Federativa do Brasil. Senado; 1988.

Brasil. Lei Orgânica da Saúde 8080 de 19 de setembro de 1990. (1990). Dispõe sobre as condições para a promoção, proteção e recuperação da saúde, a organização e o funcionamento dos serviços correspondentes e dá outras providências. Diário Oficial da União de 20 set.

Caixeta, F. C. T. A. (2008). Da Responsabilidade Civil do Cirurgião-dentista. Âmbito Jurídico, 1(57).

Carvalho Filho, J. M. M. (2014). Agente público. Direito Administrativo Brasileiro. Malheiros Editores. 
Research, Society and Development, v. 10, n. 12, e475101220815, 2021

(CC BY 4.0) | ISSN 2525-3409 | DOI: http://dx.doi.org/10.33448/rsd-v10i12.20815

Cellard A. Análise documental In: A pesquisa qualitativa: enfoques epistemológicos e metodológicos /Trad. Nasser, A.C. (2012). Ed. Vozes.

Di Pietro, M. S. Z. (2014). Direito Administrativo Brasileiro. (34a ed.), Malheiros Editores.

Ferreira, M. R., Terada, A. S. S. D., Araújo, L. G., Paz, D. C., Dezem, T. U., \& Silva, R. H. A. (2018). Correlação entre reclamações de consumidores e ações judiciais por falhas na prestação de serviços odontológicos no estado de São Paulo, Brasil. Rev Bras Odontol Leg RBOL. 5(1):30-39.

Lima, R. B. W., Moreira, V. G., Cardoso, A. M. R., Nunes, F. M. R., Rabello, P. M., \& Santiago, B. M. (2012). Levantamento das jurisprudências de processos de responsabilidade Civil Contra Cirurgiões-Dentistas nos Tribunais de Justiça Brasileiros. Revista Brasileira de Ciências da Saúde, $16(1)$, 49-58.

Lyra, M. C. A. R., Pereira, M. M. M. A., \& Musse, J. O. (2019). A obrigação de resultado nas ações de responsabilidade civil do cirurgião-dentista no Brasil, em 2017. Rev Bras Odontol Leg RBOL.; 6(3):47-58.

Mendes, D. A. G., Faria, P. H. P., Reis, J. A. S., \& Galo, R. (2021). Levantamento das Jurisprudências de Processos de Responsabilidade Civil contra Cirurgiões-Dentistas no Tribunal de Justiça do Estado de Minas Gerais, Brasil, 2014-2018. Brazilian Journal of Health Review, 4, $2600-2609$.

Moraes, A. (2009). Direito Constitucional. Atlas.

Oliveira, M. L. L. (1999). Responsabilidade Civil Odontológica. Del Rey, 349p.

Paula, F. J., Muñoz, D. R., Silva, M. D., \& Motta, M. V. D. (2006-2010). Reclamações fundamentadas sobre o tratamento dentário no Procon da cidade de São Paulo. Revista da Associação Paulista de Cirurgiões Dentistas. 67(1):56-63.

Pereira, A. W. (2004). A Responsabilidade Civil do Cirurgião-dentista em Face ao Código de Defesa do Consumidor. 22p., Monografia. Universidade Federal de Uberlândia, Minas Gerais.

Pierri, J. C. C. (2021). Diferenças entre assistência jurídica, assistência judiciária e justiça gratuita. Revista Saber Digital, 1(1), 1-11.

Saliba, N. A., Moimaz, S. A. S., Fadel, C. B., \& Bino, L. S. (2010). Saúde Bucal no Brasil: uma nova política de enfrentamento para a realidade nacional. Revista Odontológica do Brasil Central, 19(48).

Silva, M. (1999). Documentação em odontologia e sua importância jurídica. Odontol e Sociedade. (1):1-3. 